\title{
Digitalization of Small Retail Stores - Challenges in Digital Payments
}

\author{
Ravi Seethamraju \\ University of Sydney Business School, Australia \\ ravi.seethamraju@sydney.edu.au
}

\author{
Krishna Sundar Diatha \\ Indian Institute of Management Bangalore, India \\ diatha@iimb.ac.in
}

\begin{abstract}
The traditional business model of small retail convenience stores in India is increasingly under threat due to the entry of large supermarket chains and online retailers. This study, using a qualitative methodology and the Technology-OrganizationEnvironment framework as the theoretical basis, investigated the digitalization of small retail stores. Our study found low levels of adoption of digital technologies for managing supply-side and customerside processes and a heavy dependence on cash and credit-based low value transactions. Inefficient processes, poor physical infrastructure, inadequate access to and poor reliability of digital technologies, and the costs are limiting the digitalization by small retail stores. Expressed ambiguity and inherent contradictions regarding the benefits of transparency, perceived sense of control, tax implications and mistrust in the external regulations in digital context denote the small retailers' incapacity to comprehend the changes and resources required to meet the challenges.
\end{abstract}

\section{Introduction}

Digitalization is rapidly changing the retailing landscape. The central aspect of digitalization, ecommerce, is growing steadily in developing countries such as India. India is expected to surpass US as the second largest market in the world and reach US\$64 billion by 2020 . While most retail sales in India still take place in physical stores, the implications of digitalization for small retail stores are likely to be significant. Although digital and mobile technologies are widely deployed in various industry sectors in India in general, very few steps towards digitalization of small retail (kirana) stores have been taken. Large retailers and e-Commerce players have exhausted all the avenues of improving cost efficiencies in the retail supply chain and started emulating some of the characteristics of small retail stores [1]. Consequent increase in competition from them have hastened the decline of such physical stores [2], [3].

Increased competition and changed customer expectations are expected to act as drivers for innovation for small and medium sized enterprises [SMEs], as they are traditionally characterized by flexibility. There have been adjustments, adaptations and new retailing concepts that have strengthened the role of the physical store [1]. To these, the challenge of adjusting to the current and emerging digital technologies is pushing the small retail stores to the edge. It is imperative for these small retail stores to survive and grow in Indian retail context, given their national economic and social significance.

With declining market share and increasing competition, can these small retail stores in India cope with the emerging digitalization challenge? Traditional retailers in general and small retail stores in particular do not value technology highly and are generally slow in adopting information technologies [1, 2 and 4].

Small retailers, to survive, must take advantage of the digital payment systems and other digital technologies that include mobile, social media and analytics, and refocus on flexibility and new forms of customer engagement enabled by those technologies. This study investigates this adoption of digital payments by small retail stores, in a developing country like India. It aims to analyze the costs and benefits of digitalization for small retail stores and will identify organizational, technological and environmental challenges faced by them.

This paper is organized as follows. It first presents a review of the literature that explains the adoption of digital technologies in the retail sector. It will then explain the theoretical framework and research methodology adopted in this study. This is followed by the analysis, discussion of findings, implications and conclusions.

\section{Literature review}

Retail convenience grocery stores, similar to corner grocery stores o convenience stores or milk bars in 
Western countries, are called 'kirana' stores in India. They are commonly owner managed with little hired help, small, and stock a very limited number of items [4]. Spread across the country in cities, towns and villages and conveniently located in residential areas, these small retail stores stock products according to the needs of local consumers [5]. Typically, they store a small range of essential food items, grains, processed food, dry goods, drinks, toys, fresh food, personal care items and household items [6] within an area less than 500 square feet [7].

Stocking around 1000 to 8000 SKUs (stockkeeping units) of branded, unbranded and local products, these small retail stores localize their merchandise based on the ethnicity of their trading area in a diverse country like India and are more a source of livelihood for many owners rather than a vocation [8]. These stores are similar to corner grocery stores in western countries, which exist to meet emergency and fill-in requirements.

From an economic point of view, these small retail stores in India are more significant than in Western countries. India has the highest retail density in the world with one retail store per 100 people [10]. In addition to serving the needs of local community, some of these stores play a critical role in the government public distribution system. By providing food grains to rural and urban poor at government subsidized prices, some of these small retail stores play an important social role in the government poverty alleviation and social development programs. Next to agriculture, this sub-set of the retail sector in India employs 12 million people and contributes to $12 \%$ of GDP [9]. Despite urbanization and the advent of supermarket chains and online retailers, these small retail stores control $98 \%$ of the grocery retail market in India [11].

The traditional business model of these small stores typically relies on low capital investment, family ownership [12], low margins [8], low value but frequent purchases by customers, heavy dependence on cash-based transactions, easy credit terms to customers [12], and localization of the merchandise based on ethnicity, home delivery and personalized service. Characterized by low levels of technical and accounting standardization [6], these stores operate more like a small supermarket and compete by meeting the needs of the local community via a mix of merchandise, credit, home delivery and personalized service [9].

The traditional model of these small retail stores, in operation for over a century in Indian urban and rural areas, is being threatened by the entry and expansion of large retailers, malls, supermarkets and online ecommerce players. Growth in the middle-class consumer segment and high disposable income, together with changes in the Indian economy, have contributed to changes in retail preferences in India [5]. In response large retailers are aggressively establishing small format stores, similar to kirana stores, aimed at taking away their market share [14]. Further, disruptive trends, such as the rise of mobile and digital technologies, crowdsourcing, the Internet of Things (IoT), and the make-in-India movement have all had an impact on these small retail stores [15].

The literature on small retail/convenience stores has explored several issues relating to their operation and business models including consumers' choice of store, antecedents to consumer behaviour, services offered by retail stores and supply chain management practices. For example, in a study of customer loyalty, Goswami and Mishra (2009) observed strong positive influence of helpful and trustworthy sales people, home shopping, cleanliness, special offers and quality, but a negative influence in relation to travel convenience and location [7]. In India, rural and suburban consumers prefer small retail stores because of the availability of credit [13].

Digitalization, defined as the adoption and use of digital and mobile technologies, involves not only investment in those technologies but also training and actual usage [16]. Digitalization thus involves changes in organizational strategy, business processes, organizational learning and knowledge, and the whole socio-technical system, potentially impacting organizational performance [17]. Despite widespread adoption of mobile and digital technologies in every other sector in India, uptake of these technologies in the retail sector in general is limited, especially in these small retail stores and their supply chains [18]. Although many retailers want to adopt technology, because it can help them understand consumer goals and better distribute instore information, not many do so in practice because of the delay in realizing the benefits of technology adoption [18]. Consumers, on the other hand, have been keen to adopt digital technologies and believe that doing so helps them make more informed choices in buying. Adoption of digital technologies, however, may not positively influence store loyalty [19], and therefore may pose a challenge for small retail stores to remain competitive.

Amongst various digital technologies accessible to consumers and retailers, smart phones are popular in India and are increasingly integrated into everyday life, including retail shopping. The smart phone is a digital technology that not only is reconfigured as it is being used but also reconfigures the activities of the users of the device [20]. More and more consumers in both developed and developing countries are using smart phones for shopping, researching products and stores, making shopping lists, checking product availability, 
price comparison and sharing their views on products and services.

Prior studies on mobile shopping have focused on attitudes [21], acceptance of mobile technology [22] and consumers' reaction to mobile marketing [23]. There, however, have been limited studies on the effects of digitalization on consumer shopping behavior, purchasing processes and on the reconfiguration of retail stores' operations [24]. Very little is known about how these technologies are deployed by and impacted small retail outlets [31].

Because these small retail stores have rudimentary infrastructure, poor accounting and management processes, depend heavily on cash and credit-based transactions, and have low levels of adoption of mobile and information technologies, they are therefore vulnerable to the disruptive trends identified earlier [9]. Governments in India are also encouraging the adoption of digital technologies such as cashless transactions and digitized processes in the retail sector, in order to counter the black economy and to improve the overall efficiencies in retail sector and leakages in the government subsidy programs.

Large manufacturers/distributors (suppliers) have gradually adopted digital technologies that include mobile and internet technologies. Further, they have deployed other information-based digital applications such as enterprise resource planning systems, digital payments, electronic data interchange, RFID (radiofrequency identification tags) and supply chain management systems and achieved improved information visibility and sharing among partners. Regarding the small retail stores in their eco-system, however, no discernible impact has been identified.

Small retail stores appear to be disconnected from the development and adoption of digital technologies by their customers and their supply chain partners [24]. Understanding the factors that could potentially influence the adoption and continued use of digital technologies by these small retail stores and the challenges they face is critical, for them to remain competitive in the retail sector. The next section outlines the research questions, theoretical framework and research methodology.

\section{Research framework and methodology}

\subsection{Research questions}

Given the paucity of research in the Indian retail context in general and specifically on these small retail stores, this study aims to investigate the adoption of one subset of digitalization, i.e. digital payments, and attempts to fill the research gap. This study aims to analyze the costs and benefits of adopting digital payments by these small retail stores and identify the external (environmental), organizational and technology related constraints that could potentially limit their successful adoption and use. Because of the limited research and their economic significance, findings will have significant implications for research and public policy. Next section explains the theoretical framework used to investigate the above research questions.

\subsection{Theoretical framework}

Several theoretical models for the adoption of digital technologies have been used in the prior literature. Amongst them, most widely applied are Tornatzky and Fleischer's (1990) technologyorganization-environment (TOE) framework [25], Davis et al (1989) the technology acceptance model (TAM) [26], Roger's (1995) diffusion of innovation (DOI) theory [27], Aizen's (1991) theory of planned behaviour (TPB) [28] and Venkatesh et al (2003) unified theory of acceptance and use of technology (UTAUT) [29]. While the UTAUT, TAM and TPB models apply to the individual level, the DOI and TOE frameworks are useful to understand technology at the firm level [30]. The TOE framework focuses specifically on the factors of technology, organization and environment and has been tested and validated in several studies [31].

Small retail stores in our study are SMEs with owner-managers and individual entities that operate in the retail eco-system in India. Several studies in the past have successfully used TOE framework for investigating the adoption of information technologies by SMEs. For example, Pool et al (2015) studied the acceptance of RFID in Iranian SMEs using TOE framework and found the model effective [32]. Similarly, Ashamalia et al (2013) studied cloud computing adoption in UK SMEs and demonstrated value of TOE framework and interconnectedness of technology, organization and environmental factors [33]. Hisham et al (2017) investigated the adoption and impact of social media on Malaysian SMEs using TOE framework [34]. Further, Idris et al (2017) and Tahrini et al (2015) demonstrated the value of TOE framework as the theoretical basis in explaining the adoption phenomenon in SMEs context [35, 36].

The TOE framework supports the investigation of opportunities, antecedents and constraints for technological innovation [25] and integrates contingent organizational and environmental factors faced by firms [37]. It has been used in prior studies in which the technologies available to the firm both internally and externally have been incorporated. Although 
specific factors across the three contexts (technology, organization and environment) vary from study to study, the TOE framework has been consistently applied to afford empirical support in various IT innovation study contexts [30]. The TOE framework can identify organizational factors such as firm size, costs, internal resources and capabilities, and ownermanager characteristics, and environmental factors such as technology, support infrastructure, regulatory framework and industry characteristics [38, 39]. Amongst various factors identified, relative advantage, complexity of technology, compatibility, cost, technology and external regulations were found to be consistent across various studies on IT adoption [30]. In addition to the qualities of an innovation, these three broader contexts influence the adoption, implementation and use of innovations [25]. The TOE, therefore was considered suitable to study the adoption and use of digital payments by small retail stores.

\subsection{Research methodology}

Based on prior research and the TOE framework, our research question seeks to fill the current gap in research by identifying the technology, organization and environmental constraints that affect the adoption and use of digital payments by the small retail stores in India. It will examine how these stores adapt to the new digital environment. Very little is known about the nature and extent of adoption of digital technologies such as mobile and Internet by these small retail stores $[31,10]$. Given the nature of the research questions and the emerging stage of the research in the Indian context, a qualitative methodology with TOE as a guiding framework is considered appropriate for this research. This cross-sectional qualitative study approach involves shorter, less intensive data collection on site with more complex 'how' and 'why' questions. This provides an opportunity to explore new areas [40] and facilitates understanding of the multiple interpretations of the adoption of digital technologies by small retail stores from different perspectives of retailers, customers and suppliers [41].

The adoption of digital payments and general digitalization in these small retail stores takes considerable time and typically involves multiple actors, such as retail owners, customers and suppliers. Therefore, using semi-structured interviews, data was collected from multiple entities - the owners of these small retail stores, suppliers and customers in the retail eco-system in the state of Karnataka, India to understand the phenomenon. This approach focuses on observable facts and events in sampled retail stores and scrutinizes the activities and experiences of those involved and the contexts.
Selection of respondents was non-random and based on location, accessibility and willingness of the respondents. Researchers went to various retail stores in the area and interviewed the retail store owner, supplier (s) and customers visited that store. Thus, a total of 44 respondents were interviewed using a common interview protocol. Of these, 12 were retail store owner-managers (referred to R1 to R12), 11 were customers (referred to as C1 to C11) and 21 were suppliers (includes wholesalers and distributor's representatives who visit the retail stores regularly and are referred to as S1 to S21). The duration of each interview varied from 15 minutes to 30 minutes. After the respondents have agreed to participate in the study, at the beginning of the interview, the purpose of the study and why the participant was chosen for the study was explained by the researchers. Interviews were recorded with permission and transcribed for further analysis. A telephone follow-up was used to obtain clarification in case of ambiguity. Interview transcripts thus prepared were checked with the retail store owners and used for analysis.

Interview questions were developed according to two themes. The first set of questions explored the respondent's general perception of the experience of digitalization and the extent and nature of the use of digital instruments and digital payments, perceived benefits and costs. The second theme relate to the environment (external), individual/organizational and technology related factors that have an influence on the adoption of digital technologies including mobile and digital payments.

\section{Analysis and findings}

This section presents the key findings placed within the context of the adapted TOE framework. Based on the data analysis, we have identified external/environmental and internal factors that influence the uptake of digital payments in small retail stores. External factors include technology as well as other environmental factors such as physical infrastructure, inefficient processes, governmental regulations, tax implications and industry characteristics, while internal factors discussed include organizational and individual (retailer is ownermanager) aspects such as costs, perceived risk, loss of control and individual characteristics.

\subsection{Environmental factors}

4.1.1. Physical infrastructure. Slow internet speeds, lack of reliability of the infrastructure, access to the digital world, inefficient banking processes and 
security fears are factors impeding the digitalization of the retail operations of small retail owners. As pointed out by one consumer, when I clicked a bank on the BHIM app (a payment application), I got a server down message ... after two or three days I realized there were some glitches. I am not sure what the exact problem was, but since there was a problem, I decided not to use it. [C1]. Further, physical infrastructure, in terms of lack of reliable supply of power and access to internet in some regions, is also an issue. For example, in a less developed state, "there is a power problem, the server is down many times. I don't think it [digitalization] is possible [C3]. Small retailers cannot afford a card swiping machine and the associated infrastructure to handle digital payment. As noted by one consumer, "small provisional stores do not have card swiping option, cannot afford them, neither do they use mobile wallets nor do they have online/mobile banking; and accept cheque (only from known customer) if the amount is large. Only a few large provisional stores own a POS [point of sale] device and other facilities" [C4]. Thus, poor digital infrastructure and lack of resources such as swipe machines are constraining small retailers in the adoption of digital payments.

4.1.2. Inefficient processes. Inefficient banking processes is another constraint. The time taken by banks for processing online transactions and the consequent delay in ensuring regular updates for the receiver to check and confirm receipt of online payments is an issue for small retailers. Due to poor and inefficient banking processes, retailers are required to spend significant amount of their time and resources to deal with banks and ensure accuracy of online transactions. As pointed out by several respondents, "they [retailers] do not have time to stand in bank queues to deposit cheques or withdraw money" [C2]. "They feel they need to hire an employee just to handle cashless transactions" [C4]. "They feel it is difficult to learn the system and that consumes a lot of their time" [C4]. "There is no awareness ... if the person [customer] wants to pay by cash then he will accept only cash" [C6].

As noted by a supplier, "most of them (retail customers) don't have bank accounts and the value of purchases is low. They have 'Jan Dhan Yojana' (a small savings account where in government benefits will be deposited) type of accounts - they have no cheque book facility. RuPay card (an Indian payment card that facilitates open loop, domestic and multilateral system of payments that will allow all Indian banks and financial institutions to participate in electronic payments www.rupay.co.in) is there, but they have to go to a bank or ATM to use that. They need to go to the bank to deposit the sales proceeds of yesterday that may take an hour for them. [S16]. Another retailer noted, "it is a big problem and the main problem. Go to the bank and see the queues? Suppose I do cashless transaction and I need 5000 rupees, I have to pull down the shutters leaving the business and I have to go to the bank to withdraw money [R8]. For a small retailer, time spent in dealing with the complexity and efficiencies of the banking process is a potential loss of sales and business and therefore dissuades them from adopting digital technologies for payments.

4.1.3. Trust and regulations. 'Lack of trust' in the relevant regulatory environment is another constraint limiting digitalization in the retail eco-system. As pointed out by a supplier, "suppose I use PayTm for sending you money and it gets deducted from my account but does not get deposited in your account and you need that money, what do you do?” [S2]. Further, perceived bureaucracy, the associated challenges of paper work and dealing with various government entities are constraints to the adoption of digital technologies.

A related issue is the guarantees for the money deposited in banks. As noted by a supplier, the government is telling us to deposit money in the banks but who is giving guarantee that banks would not be bankrupt? They are giving us insurance of only Rs. 100,000 (US\$ 1400) per account holder" [S3]. Deposits beyond this amount are treated as unsecured credit by the banks in India. In a volatile reformist environment where several banks are being reorganized, merged and recapitalized in India, this fear acts as a barrier to use banking and other transparent processes through digitalization.

Lack of trust on digital systems is another challenge. "They (customers and retailers) don't have much trust on digital systems, they believe that some percentage of their amount will be cut, they rely on the receipt or slip" [S16]. "They don't know what PayTM or BHIM (Bharath Interface Money - a payment application in India) app is and some people don't have a mobile with a keypad ... can't afford smart phones, can't operate mobile and can't use Internet" [R1]. For others, "there is no account in banks, there is no money" [R10]. These responses suggest that inadequate trust in the regulatory environment, whether it is the government bureaucracy or banking or digital payment applications, negatively affects the adoption of digital payments.

4.1.4. Powerful role of suppliers. Retailers deal with low value payments in large volumes and do not see significant benefits by adopting digital payments, when 
compared with their suppliers. These suppliers, typically large distributors or wholesalers, have significant influence over the retail store owner and if necessary, could force them to adopt digitalization. "It is easy to move those shopkeepers (retail store owners) to digital because they are dependent on us (suppliers). Once we decide, we can give them one week to ten days' time and after that we (can say that we) will not accept cash transaction. We will get the payment using a swiping machine and make them (retail store owners) understand that companies (suppliers) are putting pressure on us and we cannot pay by cash. The shop keepers (retailer) will be forcefully converted because they will not get goods if they don't" [S10]. Typically, small retailers have more knowledge of the movement of a product in their local area. If digitized, this information could be more valuable to the suppliers. Suppliers, in some instances, are willing to give the retail owner, necessary equipment to digitize the processes. As pointed out by one supplier (who is a large wholesaler supplies groceries), "we are ready to give them a cash register (that could produce receipts and daily sales report); but no, they are not willing. I think its because of tax and other problems" (S5).

4.1.5. Transparency and tax implications. Potential tax implications if financial transactions are recorded and transparent is another challenge for retailers, as well as other entities in the retail eco-system that are heavily dependent upon cash-based transactions. This is inhibiting potential adoption of digital technologies. As noted by a retailer, "in cashless everything gets recorded and that exposes us to taxes. Businessmen prefer cash for transactions. They don't want transparency because they want to evade taxes" [R13]. Another observed, "we need licenses from many departments for our shops - Shops Act, VAT, drug and food safety, parvaana license and others. They (government officials) are harassing us. We will all pay whatever taxes, if there is no corruption" (R6).

Another retailer observed, "if they (suppliers) opt for cashless transaction they will have to pay more tax, one needs to show all the money and income, there will be huge tax deduction" [R2]. Online bank transfers are also rare. As noted by a retailer, "they don't accept online transfers; they are content with whatever method they are following now; if they agree for online payment they should constantly check their account" [R4]. Tax rate in India is relatively low and the number of taxpayers per capita is also low. Small entities in the retail eco-system (small retailers and small suppliers) expressed their reluctance to pay a fair share of taxes in the current environment while simultaneously expressing willingness to pay taxes in an improved corruption free efficient digital environment.

\subsection{Organizational factors}

\subsubsection{Cost of digital payments}

Digitized technologies and digital payments are expected to increase transaction efficiencies. Our study found ease of use, safety, transaction transparency, billing accuracy and convenience as the benefits of using digital technologies. As pointed out by a customer, "it is easy and safe and there is no chance of theft [C6]. Another customer believed that "it would be beneficial if everything can be done through cashless transaction, we won't need to carry cash with us, there would be no fear of theft that problem of fake notes would also be solved, as all transactions are cashless" [C8].

Accuracy of data in the retail supply chain, speed and convenience facilitated by the digitization of payments are benefits of digitalization. They help suppliers to overcome problems with invoicing. As noted by a supplier, "goods previously were dealt with (paid) in rough calculation, we are used to deal that way without demanding bills (receipts); now we get the goods with their invoices in a proper manner" [S10]. On speed and convenience, another respondent observed, "there is no need to wait and it goes from one account to another instantly; speed will be there; people also feel good because it will be easy and saves them time" [S6]. These benefits of speed, convenience, accuracy and transparency, however, are influenced by the size of the business and their role in the supply chain. Overall, potential benefits of digitization are higher and significant to suppliers than to retailers and their customers, our study found.

4.2.1. Cost of digital payments. Costs are an important constraint for the adoption of digital payments by the retail stores, given their low margins and size. Even though online banking and cashless transactions are pushed as a cheaper and more costefficient options by the government and banks, customers are aware of the costs associated with these transactions. Though these costs are absorbed by the agencies at present, it may change in future and these costs may be passed on to consumers. Consumers' choice to shift to digital payments is heavily dependent upon the technology being free. As noted by a supplier, no one will use the services if there is an extra charge for the cashless transaction and especially if a percentage is charged.

As noted by a supplier, "the margins for the retailers are already low, no retailer would prefer to use digital transactions if they are charged extra [S4]. Further, "if bank people don't cut much amount then people will like cash less as time is saved. There will 
be a growth in business. But if bankers cut 20 rupees, people also will think why we should pay 20 rupees to the bank. If we go to cinema hall they say it is 160 for cashless and 150 for cash, then why will people listen and use cashless? If banks don't tax people then people will go cashless. [S6].

While customers and retailers are not willing to choose cashless transactions because of the potential costs, suppliers, however, are willing to pay and prefer low fixed transaction costs rather than a percentage of the value. Participants also expressed concern about the temporary nature of current no-fee models of digitalization. Respondents believed that some fees whether for using ATMs (automatic teller machines) or debit cards or online transfers or third party payment gateways - will eventually be charged by financial institutions and/or governments and therefore are not keen to go digital.

4.2.2. Perceived risk. With regard to the perceived risk in digital transactions, our study observed a degree of antinomy where in respondents expressed contradictory views. While some respondents considered the security of transactions to be superior in a digital context, others expressed mistrust in external environment (explained earlier) and perceived a financial risk. There is an implicit risk in a cash-based environment, in which small retailers receive cash from customers and pay cash to suppliers/wholesalers. As noted by a supplier, "if you sell goods to me and I give cash and if other people also give me cash, it is difficult to carry that cash all the way. Earlier I have to follow and ask them when they are coming. Sometimes workers [who transport cash] tell me that the money is lost or fallen off. It is problematic especially if it is a large amount. But if it is a cheque I can ask him to block that. So that fear is not there anymore. You don't have to go to bank. You can put a cheque in drop box and it will be deposited" [S10]. At one end, digital payments, thus are considered secure and safe by some respondents.

Others, however, have regarded digital payments risky given their intangibility. As noted by a supplier, "retail business is done in cash. We can't do cashless transactions through PayTM etc. People say it takes four days to receive payment that way. It gets withdrawn from your account and it does not reach that person. Public is annoyed by that" [S2]. "People are habituated with cash and if suddenly cash becomes nil, everyone will have problems. If everybody starts using it, I have to start using it. The theft and snatching will not happen to them if we go cashless" [S10]. Though the number of people purchasing android phones is increasing day by day the number of people using cashless methods has not increased significantly" [S4]. Everything cannot be forced and implemented; people's attitude should be changed; many are not ready to pay through cashless methods even if I [a retailer] am ready to accept" [R4]. While some consider digital payments secure and safe, others view them less secure because of their intangibility and perceived loss of control, as explained further below.

4.2.3. Loss of control. People perceive a loss of control when they are dealing with digital transactions, our study found. Manual transactions are tangible and individuals feel they are in control. Online payment is perceived as abstract and intangible and consumers view this as loss of control over expenditure and transactions. Because online payments are not visible, it may cause people to spend more than they can afford, many respondents opined. As noted by a retailer, "one major psychological issue is that in case of physical cash payments one feels the pinch of money spent. When it comes to digital payment we don't feel that pinch. It is always the 'necessity' that teaches people to implement the things they have learnt" [R4].

As noted by a retailer, "in cashless transactions I won't be able to do anything, I would not get any money into my hand. If cashless transactions start in a big way, I have to get internet connection, and the government won't give that free. While the customers are waiting, I can't keep checking whether the money has gone in or not. I can't see the money" [R8]. This again leads to the issue of trust on the digitalization and the limitations of associated infrastructure.

Further, some believe cash is a useful tool to deal with contingencies and emergencies. There is an implicit assumption that cash is needed during emergencies because other operators in the economy prefer cash and/or transactions with cash are easy when one is in urgent need and constrained for time. As noted by a respondent, "if I need money urgently, how can I get that money? I can't bring that money by selling my card? Anyone can transfer money to me but I cannot get the cash. If I need money urgently to buy something in cash, I can't get that" [S10].

While some respondents indicated that digital financial transactions may be an incentive for people to spend on impulse others believe that digital payments are more secure and less emotional. As pointed out by a respondent "when my customers have cash in their hand they don't prioritize their spending. If they need something, without thinking twice they buy it if they have cash. Later to pay me or anyone else, they would not have money. This happens all the time. Now, all the customers' money will be lying in their bank account, because they can't draw it out immediately. In such case, customers do not have liquid cash to spend without thinking" [S5]. Thus, this sense of control (or 
lack of it) in relation to digital transactions, is an important factor limiting the adoption of digital technologies. As discussed above, this factor is moderated by the individual characteristics in terms of level of education, perceived benefits, individual attitudes towards digital payment and trust in the external digital environment.

4.2.4. Individual characteristics. Retailers though have a positive attitude towards digitalization, their current use of digital tools in managing retail operations is low. Though all the retail-eco system members are heavy users of mobile phones as observed in our study, they are hesitant to use digital payments. One of the reasons is their low level of education and awareness of the digital instruments and their benefits. As pointed out by a large supplier, "people are not aware now. Only $10 \%$ of people are educated. If they tell me that they have made payment and I don't receive payment after 4 days also, what would I do? Digital would not work until Indian public becomes educated. Five out of 10 people don't know what the digital transactions are" [S2]. The extent of digitalization is influenced by individual socioeconomic background, employment and education. As noted by one retailer "it is very difficult in India and especially in our state, because there are more uneducated people here; they can't make cashless transactions" [R8]. Education and socio-economic background plays a role in the adoption of technologies. Widespread use of mobile technologies for entertainment and communication purposes and limited use for retail transactions, point out to other reasons such as trust, external factors, security, perceived sense of control and others as discussed above.

4.2.5. Technology. Technology itself is a challenge. Smart phones are extensively used by consumers, retailers and suppliers in the retail eco-system for hedonistic reasons, but the payment applications are not considered reliable and not widely used. For example, BHIM [Bharath Interface for Money], a payment application based on Unified Payment Interface [UPI] for digital financial transactions, is reportedly difficult to install and operate. As noted by a supplier, "I have personally helped a few customers to install the app. It was not successful. Though some have installed it, they are not interested to use this; there must be some problem with the app too. A customer has to enter my account number and IFSC code every time to make the payment, but PayTM is comparatively easy" [S4].

Further, network effects are significant in digitalization and in the use of digital wallets such as
BHIM. As reported by a customer, "BHIM does not work even though I have created the barcode and other necessary things in that app. If I have to make payment to anyone, the other person needs to have the BHIM app too. Otherwise it is useless" [C5].. As noted by another respondent, "I have installed PayTm app as my friends have recommended it saying that they have many discount offers" [C4]. "I had a friend who earned money by adding people" [C1]. As digitalization is in its early stages in a sector that is not technology-focused, some challenges are expected. As one respondent indicated "one should be up-to-date with the technology to reap the benefits [S4]. In general, there is a recognition of the pros and cons of technology adoption. "in one way, it [technology] makes our life easy, in another way it makes us lazy, makes our life difficult" [R4]. The effectiveness and popularity of payments applications such as 'PayTM', 'Freecharge' etc. depends on network effects and their continued use may be dependent upon the continuation of the incentives currently offered.

\section{Conclusions}

Digitalization is transforming how business organizations - small and large interact and exchange value. Taking advantage of the potential benefits such as customer intelligence gathering, transaction efficiencies, transparency and extended customer reach, small retail stores have the potential to modernize their business model in the digitized environment and remain competitive. Failure to adopt digital technologies could potentially threaten their business model given changing consumer habits and preferences and increasing competition from supermarket chains and online retailers.

Small retail stores, as observed in our study, are struggling to adapt digital payments due to their inability to change characterized by the perceived risk, loss of control, individual characteristics such as low education and preference to use technology for hedonistic reasons. Though suppliers have a powerful influence on the small retail stores and make them adopt digital payments, several external factors such as inefficient banking processes, tax implications with increased transparency, poor and unreliable digital infrastructure and lack of trust on regulatory environment are inhibiting the adoption of digital payments. Our findings provide insight into the significance of physical infrastructure and its role in facilitating digital technologies, as well as how excessive bureaucracy and inadequate trust in the regulatory environment impact adoption. Information campaigns as part of national digital strategy are 
necessary to educate the retail store owners and their customers considering the general lack of trust in the external institutions, poor awareness of digital payment processes and general skepticism of change. Offering financial incentives to small retailers that are chronically under-resourced though is expedient, uptake of digital payments and their sustained use requires sound supporting structures and reliable digital environment facilitated by the governments. If such support is not made available, aggressive expansion and adoption of small retail formats by the supermarket chains could pose direct threat to these small retail stores. Considering their social and economic significance, governments should push digitalization efforts in this transformative phase of retail sector in India.

Our study has shown the suitability of TechnologyOrganization-Environment (TOE) framework to study the adoption of digital payments. In the retail supply chain, powerful influence of external factors, internal features characterized by individual owner-manager's perceptions, and different stages of adoption and use of digital and mobile technologies allow for refinement of the TOE framework by drawing concepts from Diffusion of Innovation (DOI) theory. The findings of this study have practical implications for government agencies, financial institutions and technology companies seeking to simplify and build trust in relation to the regulatory environment, and to improve accessibility and ease of use of various digital applications.

Although this study focuses on small retail stores in India, findings will be applicable to small owner operated retail stores affected by online retailers, large supermarket chains and digitalization anywhere in the world. Challenges identified in this study though are not unique to Indian context, their economic and social significance demands the development of support structures for digitalization imperative for governments in India.

In addition to the usual limitations of case study research, the ambiguity and contradictory views observed on issues such as perceived sense of control, transparency of transactions, security and tax implications have made the generalizability of findings difficult. Another limitation relating to the use of Technology-Organization-Environment (TOE) framework could be overcome by integrating constructs from diffusion of theory and technology acceptance models. Overall, our study contributes to the body of research on technology adoption in the retail sector and highlights the potential impact of digitalization on the business model of small retail stores.
If small retail stores do not adopt to digitalization, consumers may shift their loyalty. All the advantages of convenient shopping hours, credit facilities and localized services offered by these small retail stores, and them being an integral part of the local community, may not help them retain consumer patronage. Small traders in villages and countryside especially will gradually disappear with dire social and economic consequences if there is no governmental intervention and support. Without leveraging the power of digital technologies, small retailer cannot prevent the inevitable impact on their business models. Even though an antinomy of their views on digitalization and their incapacity to comprehend the challenges are concerning, retailers, however, seem to have recognized the changing times. As aptly observed by one respondent, "there is no one to blame, as time changes such changes happen and we too will have to change (and adapt)" [R7]. To survive, small retail stores must recognize the inevitable impact digitalization could have on their business models and adapt.

\section{References}

[1] J. Hagberg, M. Sundstrom and N. Egels-Zanden, "The Digitalization of Retailing: An Exploratory Framework," International Journal of Retail Distribution Management 44(7), 2016, pp. 694-712.

[2] M. Corkery, "Is American Retail at a Historic Tipping Point?” New York Times, 16 April 2017.

[3] H. Peterson, "The Retail Apocalypse has Officially Descended on America.” Business Insider, downloaded from Http://Nordic.Businessinsider.com, 21 March 2017.

[4] L. Ramakrishnan, "The Competitive Response of Small, Independent Retailers to Organized Retail: Study in an Emerging Economy,” Journal of Retailing and Consumer Services, 2010, 17(4), pp. 251-258.

[5] D. Sathish and V.D. Raju, "The Growth of Indian Retail Industry,” Advances in Management, 2010, 3(7), pp. 15-19. [6] M. Maruyama and L.V. Trung, "Traditional Bazar or Supermarkets: A Probit Analysis of Consumer Perceptions in Hanoi," International Review of Retail, Distribution and Consumer Research, 17(3), 2007, pp. 233-252.

[7] P. Goswami and M.S. Mishra, "Would Indian Consumers Move from Kirana Stores to Organized Retailers When Shopping For Groceries?” Asia Pacific Journal of Marketing and Logistics [21:1], pp. 127-143.

[8] E. Rani, "Supermarkets vs. Small Kirana Stores,” Journal of Business and Management, 10(1), 2013, pp. 1-7.

[9] P.K. Sinha, S. Gokhale and S. Rawal, "Online Retailing Paired with Kirana - A Formidable Combination For Emerging Markets," Customer Need and Solutions, 2, 2015, pp. 317-324.

[10] A. Kalhan and M. Franz, "Regulation of Retail: Comparative Experience," Economic \& Political Weekly, XLIV (32), 2009, pp.56-64. 
[11] Kotak Institutional Equities (KIE), "98\% of Grocery Retail Market is controlled by Kirana Stores: Study." Economic Times Brand Equity, PTI, 1 February 2016, [12] Z-S. Yun, D.T. Pysarchik and C.S. Dabas, "The Determinants of Retail Loyalty of Indian Consumers." Journal of Food Products Marketing, 18(4), 2012, pp. 268286.

[13] G.K. Saini and A. Sahay, "Comparing retail formats in an emerging market: Influence of credit and low price guarantee on purchase intention," Journal of Indian Business Research, 6(1), 2014, pp. 48-69.

[14] Business Standard. 2015. "Kirana Stores the Inspiration for Big Retails Small Stores: BCG,” Business Standard Reporter, Business Standard Reporter, 16 September 2016. [15] Deloitte [2012], "Digital Disruption: Short Fuse or Big Bang,” Deloitte Touche Tohmatsu, Australia, 2012.

[16] A. Burton-Jones and M. J. Gallivan, "Toward a Deeper Understanding of System Usage in Organisations: A Multilevel Perspective.” MIS Quarterly, 2017, 31(4), pp. 657-680.

[17] W.J. Orlikowski, "The Socio-materiality of Organisational Life: Considering Technology in Management Research," Cambridge Journal of Economics, 34(1), 2009, pp. 125-141.

[18] E. Pantano and M. Viassone, "Demand Pull and Technology Push Perspective in Technology-Based Innovations for the Points of Sale: The Retailers Evaluation,” Journal of Retailing and Consumer Services, 21(1), 2014, pp. 43-47.

[19] S. Renko and M. Druijanic, "Perceived Usefulness of Innovative Technology in Retailing: Consumers? And Retailers Point of View," Journal of Retailing and Consumer Services, 21(5), 2014, pp. 836-843.

[20] C. Fuentes, K. Backstrom and A. Svingstedt, "Smartphones and the Reconfiguration of Retailscapes: Stores, Shopping and Digitalization," Journal of Retailing and Consumer Services, 39, 2017, pp. 270-278.

[21] C. Fuentes and A. Svingstedt, A. 2017. "Mobile Phones and the Practice of Shopping: A Study of How Young Adults Use Smartphones to Shop," Journal of Retail Consumer Service, 2017, 38, pp. 137-146.

[22] S. Agrebi and J.I. Jallais, "Explain the Intention to Use Smartphones for Mobile Shopping," Journal of Retail Consumption and Service, 22, 2015, pp. 16-23.

[23] H.F. Lin, "Contextual factors affecting knowledge management diffusion in SMEs," Industrial Management \& Data Systems, 2014, 114(9), pp. 120-141.

[24] K-Y. Goh, J. Chu and J. Wu, "Mobile Advertising: An Empirical Study of Temporal and Spatial Differences in Search Behaviour and Advertising Response," Journal of International Marketing, 2015, 30, pp. 34-45.

[25] J. Hagberg and C. Fuentes, "Retail Formations: Tracing the Fluid Forms of an Online Retailer." Consumer Markets \& Culture, 2018, https://doi.org/10.1080/10253866.2018.

[26] L.G. Tornatzky and M. Fleischer, The Processes of Technological Innovation. Lexington, Lexington Books, 1990.

[27] F.D. Davis, R.P. Bagozzi and P.R. Warshaw, "User Acceptance of Computer-Technology - A Comparison of 2
Theoretical Models,” Management Science, 1989, 35(8), pp. 982-1003.

[28] E.M. Rogers, "Diffusion of Innovations," New York: The Free Press, 1995.

[29] I. Ajzen, "The Theory of Planned Behaviour," Organizational Behavior and Human Decision Processes, 50, 1991, pp. 179-211.

[30] V. Venkatesh, M.G. Morris, G.B. Davis and F.D. Davis, "User Acceptance of Information Technology: Toward A Unified View.” MIS Quarterly, 27(3), 2003, pp. 425-478.

[31] T. Oliveira and M.F. Martins, "Literature Review of Information Technology Adoption Models at Firm Level," The Electronic Journal Information Systems Evaluation, 14(1), 2011, pp. 110-121.

[32] L. Bollweg, R. Lackes, M. Siepermann, and A. Sutaj, and P. Weber, "Digitalization of Local Owner Operated Retail Outlets: The Role of the Perception of Competition and Customer Expectations.” In PACIS 2016 Proceedings, 348, 2016.

[33] J.K. Pool, S.M. Arabzad, A. Asadi and M.R. Ansari, "RFID acceptance of SMEs using TOE Framework: An empirical investigation of Iranian SMEs,” International Journal of Logistics Systems and Management, 2015, 21(3), pp 335-347.

[34] Y. Alshamailinva, S. Papagiannidis, S. and F. Li, 2013. "Cloud computing adoption by SMEs in the north east of England: A multi-perspective framework," Journal of Enterprise Information Management, 2013, 26(3), pp.250275.

[35] M. Hisham, M. Sharif, K. Rosli and A. Ahmi, "A Model of Social Media Adoption and Impact on Malaysian Small and Medium-sized Enterprises [SMEs]," in Proceedings of the International Conference on E-Commerce [ICoEC 2017], 18-20 September, Putrajaya, Malaysia, 2017, pp.1-5.

[36] A. Idris, H. Edwards and S. McDonald, "E-commerce adoption in Developing Countries SMEs: What Do the Prevailing Theoretical Models Offer Us?” in Proceedings of the International Conference on E-Commerce [ICoEC 2017], 18-20 September, Putrajaya, Malaysia, 2017, pp.1-5.

[37] A. Tarhini, N.A.G. Arachchilage, R. Masadeh and M.S. Abbasi, "A Critical Review of Theories and Models of Technology Adoption and Acceptance in Information Systems Research,” International Journal of Technology Diffusion, 6(4), 2015, pp.58-77.

[38] K.K. Kuan and P.Y.K. Chau, "A Perception-based Model for EDI Adoption in Small Business Using a Technology-Organization-Environment Framework," Information and Management, 38(8), 2001, pp. 507-521.

[39] S. Quinton, A. Canhoto, S. Molinillo, R. Pera and T. Budhathoki, "Conceptualizing a digital orientation: antecedents of supporting SME performance in the digital economy,” Journal of Strategic Marketing, 26(5), 2018, 427 439.

[40] H. K. Klein and M.D. Myers, "A Set of Principles for Conducting and Evaluating Interpretive Field Studies in Information Systems,” MIS Quarterly, 23(1), 1999, pp. 6794.

[41] R. Yin, Case Study Research: Design and Methods, London, Sage 2009. 